\title{
Caracterização de estruturas anatômicas de órgãos de plantas cultivadas no Nordeste com produção de aulas práticas para anatomia e morfologia vegetal
}

\section{Characterization of anatomical structures of plant organs cultivated in the Northeast with the production of practical classes for plant anatomy and morphology}

\author{
Israel Paulo da Silva Junior ${ }^{(1)}$; Dacio Rocha Brito ${ }^{(2)}$. \\ (1) Universidade Estadual de Alagoas - UNEAL, Graduando em Ciências Biológicas, \\ E-mail: israelpaulojr94@gmail.com
}

2) Universidade Estadual de Alagoas - UNEAL, Docente do Curso de Ciências Biológicas, E-mail: dacio@uneal.edu.br

\begin{abstract}
Resumo - As aulas práticas no ensino da Botânica, no caso em especial do ensino da morfologia e anatomia vegetal, são fundamentais no processo de ensino aprendizagem nas escolas de educação básica, e os estudantes de licenciatura em biologia necessitam construir um conhecimento durante a graduação através da experimentação, se inserindo na iniciação científica dentro da universidade. É papel da universidade desenvolver conhecimento científico que permita ao futuro docente aplicar esse saber construído com um talento. Nas escolas da região de Arapiraca, no Estado de Alagoas observam-se dificuldades no processo de ensinoaprendizado por parte dos professores para ministrar as disciplinas de Biologia Vegetal, bem como as dificuldades encontradas pelos alunos para sua compreensão. Por outro lado, as graduações em licenciatura requerem permanentemente desenvolvimento de novas ferramentas para o ensino em sala de aula nas escolas de educação básica, sem, contudo, distanciar o aluno de sua realidade e transformar o ensino em algo satisfatório. Verifica-se ainda que nos pressupostos dos Parâmetros Curriculares Nacionais (PCNs), cita que nas escolas não se deve ter um modelo curricular homogêneo e impositivo, além disso, observa-se em muitos livros didáticos o exemplo de plantas desconhecidas na região, como é o caso do autor Paulino (2005) que cita o Baobá como planta de região seca, comum em Madagascar, África, entre outros. Por essa razão, objetivou-se com esse trabalho, considerando que a utilização de práticas pedagógicas adequadas é essencial e permite o conhecimento associando a teoria à prática, desenvolver aulas práticas de laboratórios no ensino da biologia vegetal, de fácil manuseio, permitindo investigação pelos discentes, utilizando plantas conhecidas, aplicáveis para educação superior e para o ensino fundamental e médio.
\end{abstract}

Palavras-chave: Aulas práticas, botânica, histologia vegetal.

Abstract - The practical classes in the teaching of Botany, in the special case of teaching
morphology and plant anatomy, are fundamental in the process of teaching learning in basic
education schools, and undergraduate students in biology need to build a knowledge during
graduation through experimentation, inserting themselves in scientific initiation within the
university. It is the role of the university to develop scientific knowledge that allows the future
teacher to apply this knowledge built with talent. In schools in the region of Arapiraca, in the
state of Alagoas, difficulties are observed in the teaching-learning process by teachers to teach
the subjects of Plant Biology, as well as the difficulties encountered by students in 


\section{Revista Ambientale \\ Revista da Universidade Estadual de Alagoas/UNEAL \\ e-ISSN 2318-454X, Ano 13, Vol. 13 (2), 2021}

understanding them. On the other hand, undergraduate degrees permanently require the development of new tools for classroom teaching in basic education schools, without, however, distancing the student from their reality and transforming the teaching into something satisfactory. It is also verified that in the assumptions of the National Curricular Parameters , he cites that in schools one should not have a homogeneous and imposing curricular model, besides the example of unknown plants in the region is observed in many textbooks, as is the case of the author Paulino (2005) who cites Baobab as a plant of dry region, common in Madagascar, Africa, among others. For this reason, the aim of this work was to consider that the use of adequate pedagogical practices is essential and allows knowledge associating theory with practice, to develop practical laboratory classes in the teaching of plant biology, allowing investigation by the students, using known plants, applicable for higher education and for elementary and high school.

Keywords: Practical classes, botany, plant histology.

\section{Introdução}

As aulas de biologia são vistas por muitos alunos como algo para memorização de conceitos e nomes complicados a serem compreendidos, além disso, sabemos que a escola deve trabalhar a realidade dos alunos e transformá-los em cidadãos conscientes e que o processo de aprendizagem pode ser mediado pela ação do professor utilizando novas metodologias, despertando o interesse em aprender (CALLEGARIO E BORGES, 2010). Dillenbourg, (2000) já havia dito que o sistema educativo precisa desenvolver instrumentos para facilitar e tornar o processo de aprendizagem mais prazeroso e compatível com as habilidades perceptivas e cognitivas do aprendiz, fato que corrobora com a ideia de Callegario e Borges.

Por outro lado, cabe salientar que para as graduações em licenciatura, em especial, devese observar o citado por Mendes e Munford, (2005) que além de atualizar os conhecimentos científicos, de buscar a descoberta de novos materiais e novas metodologias pedagógicas, o futuro professor necessita também de espaço para a reflexão sobre o fazer pedagógico por meio de leituras, pesquisas específicas e trocas de experiências.

No Brasil a educação vem sofrendo intervenções e implementação de novas tecnologias na educação, e com isso, o processo de interesse pelas aulas influencia os alunos a aprender de forma lúdica, além de atualizar os conhecimentos científicos, contudo, no caso do ensino de Ciências é possível destacar a dificuldade dos alunos em relacionar sua convivência com situações passadas na sala de aula, e não reconhece o conhecimento científico em situações do seu cotidiano.

De acordo com Queiroz (2016), é através da experimentação que o aluno vai além da praticidade, descobre um mundo que até então, não é da realidade. É uma estratégia que mostra de forma simples e divertida, permitindo que o aluno tenha o conhecimento prático da teoria.

Os conhecimentos produzidos nas instituições de ensino superior auxiliam no ensino da biologia, sobretudo se as atividades práticas são inseridas na metodologia do ensino de biologia. 


\section{Revista Ambientale \\ Revista da Universidade Estadual de Alagoas/UNEAL \\ e-ISSN 2318-454X, Ano 13, Vol. 13 (2), 2021}

Em muitos livros didáticos, por exemplo, verificam-se muitos exemplares de plantas desconhecidas na região, como é o caso do autor Paulino (2005) que cita o Baobá como planta de região seca, comum em Madagascar, África. Outro exemplo verifica-se no livro de Lopes, (2002) onde o autor utiliza erroneamente a imagem de uma cactácea diferente como sendo um mandacaru, no caso pode até ser que o nome popular da plantas na região do autor seja mandacaru, entretanto, tal fato reforça a necessidade do uso de plantas conhecidas pelos discentes durante as aulas práticas de biologia vegetal. A maioria dos livros abordam em seus materiais didáticos, práticas laboratoriais com diversos tipos plantas e dão como sugestão, por exemplo, em sua maioria o uso a planta Elodea para aulas práticas e teóricas, planta que nem sempre são encontradas nas escolas da região nordeste.

Atentando para os pressupostos dos Parâmetros Curriculares Nacionais (PCNs), que traz em seu contexto uma proposta flexível, a ser concretizada nas decisões regionais e locais sobre currículos e sobre programas de transformação da realidade educacional empreendidos pelas autoridades governamentais, pelas escolas e pelos professores, não se deve ter um modelo curricular homogêneo e impositivo, que se sobreporia, entre outros, à diversidade sociocultural das diferentes regiões do País ou à autonomia de professores e equipes pedagógicas. Portanto o uso de plantas conhecidas pelos professores e alunos pode de forma flexível adequar o currículo a realidade local, desde que esteja dentro de sua proposta pedagógica, motivando assim o aprendizado e aumento dos conhecimentos dos alunos.

Apesar de ocorrerem dificuldades inerentes ao uso do Laboratório de Ciências, conforme Marandino (2009) muitos professores desejam ampliar as oportunidades de atividades práticas laboratoriais para os estudantes, mas nem sempre conseguem superar as dificuldades no cotidiano escolar. Porém, considerando que a função do experimento é fazer com que a teoria se adapte à realidade, a atividade educacional poderia ser feita em vários níveis dependendo do conteúdo, da metodologia adotada ou dos objetivos que se quer com a atividade.

Enfim, a experimentação é uma atividade essencial no ensino de Ciências e caso não ocorra o discente pode até compreender os conteúdos ministrados na universidade, mas terá dificuldades para aplica-los, pois vivenciar aulas práticas pode-se construir melhor o conhecimento melhorando sua formação. Servem também, segundo Leite (2005), como estratégia e podem auxiliar o professor a construir com os alunos uma nova visão sobre um mesmo tema.

Logo, a utilização de práticas pedagógicas adequadas é essencial e permite o conhecimento associando a teoria à prática promove melhores condições de aprendizagem aos alunos, e em particular pode potencializar a elaboração do conhecimento, caso os estudos estejam ligados ao cotidiano. Assim, este trabalho tem como objetivo desenvolver aulas práticas de laboratórios no ensino da biologia vegetal, permitindo investigação pelos discentes na área de morfologia e anatomia vegetal, com o uso de plantas conhecidas, aplicáveis para educação superior e para o ensino fundamental e médio.

\section{Procedimento metodológico}

O experimento foi realizado no laboratório multidisciplinar do Curso de Ciências 
Biológicas, Campus I, da Universidade Estadual de Alagoas, localizada na Rua Governador Luís Cavalcante, s/n - Alto do Cruzeiro, Arapiraca - AL, 57312-000, latitude 944'54.0"S, longitude $36^{\circ} 39^{\prime} 13.8^{\prime \prime} \mathrm{W}$.

Os órgãos vegetais das espécies selecionadas foram estudados morfologicamente e anatomicamente, ou seja, externa e internamente logo após serem colhidas e levadas para o laboratório.

Para estudos morfológicos utilizou-se lupas e para os estudos anatômicos foram utilizadas lâminas para microscopia, estiletes, lâminas cortantes, lamínulas, vidro de relógio, placa de Petri, corantes, isopor, microscópios e corantes vitais necessários ao estudo e, naturalmente, plantas (Figura 1).

Figura 1. Materiais de laboratório utilizados para preparação de lâminas e a planta Girassol (Helianthus annuus L.), uma das espécies usadas.

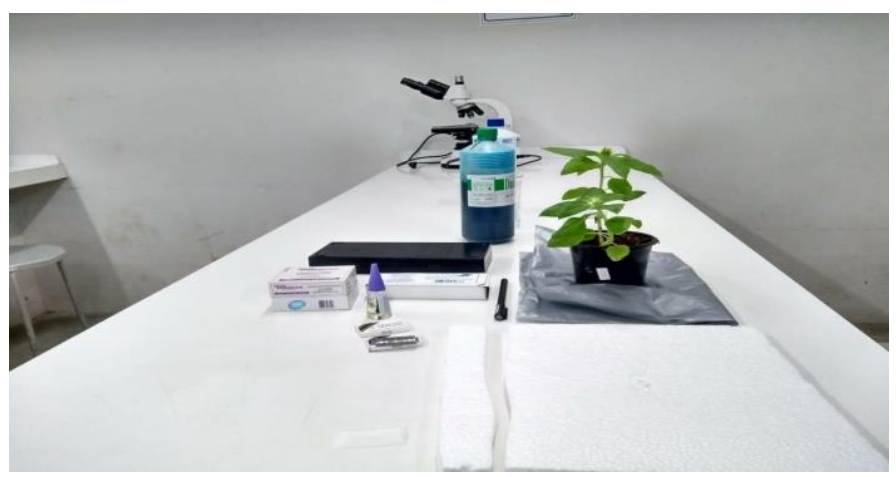

Fonte: Arquivo da pesquisa. Autora: SANTOS, M. I. G.

No laboratório multidisciplinar foram feitos cortes nos órgãos vegetais e preparo das lâminas provisórias das folhas, caules e raízes, sendo esses cortes feitos à mão livre e observados em microscópios óptico simples (Figura2).

Figura 2. Preparo e visualização de lâminas preparadas.

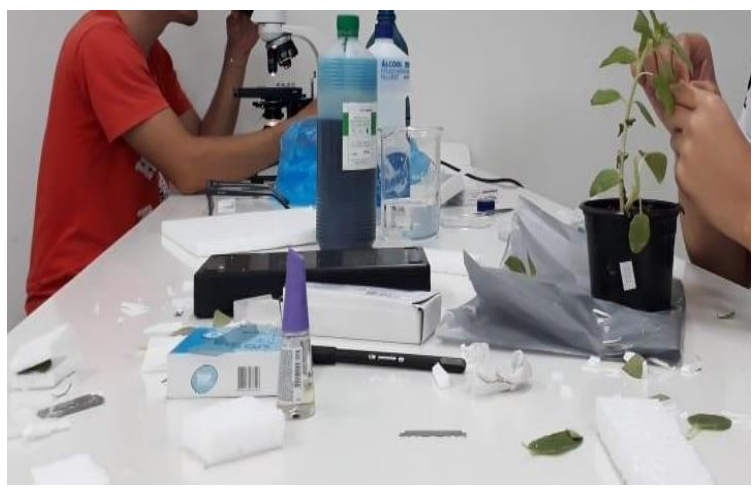

Fonte: Arquivo da pesquisa. Autora: SANTOS, M. I. G. 


\section{Revista Ambientale \\ Revista da Universidade Estadual de Alagoas/UNEAL \\ e-ISSN 2318-454X, Ano 13, Vol. 13 (2), 2021}

Para as folhas foram feitos cortes paradérmicos, objetivando observar a epiderme abaxial e adaxial, e corte vertical, objetivando a visualização dos tecidos. Destaca-se que foi utilizado esmalte incolor, aplicado sobre as folhas durante o dia e a noite, objetivando verificar células epidérmicas, e que após secar, retirou-se o esmalte com uma pinça e o corte foi levado ao microscópio para observação, em especial verificar os estômatos.

Para raízes, caules e flores os cortes foram transversais, buscando a observação dos tecidos internos. Os cortes histológicos dos órgãos vegetais realizados resultaram em camadas finas dos diversos tecidos vegetais e com eles, foram preparadas lâminas temporárias, e posteriormente as lâminas foram observadas ao microscópio. Os microscópios ópticos utilizados foram de pouco aumento, pois são os comumente encontrados nas escolas do ensino básico.

Utilizou-se corantes, tais como Lugol, que reage com o amido dando uma coloração azulnegra ou marrom escuro. Sudan III, que reage com compostos graxos de cadeia longa como a suberina e a cutina dando uma coloração de amarelo-alaranjado ao vermelho. Azul de astra, que reage com a celulose dando uma coloração azul. Fucsina básica, que reage com a lignina dando uma coloração vermelha. Azul de toluidina, que reage com as paredes lignificadas dando uma coloração azul esverdeado e reage também com paredes celulósicas dando uma coloração roxa e azul de metileno, que reage com a celulose e com núcleo e estruturas do núcleo.

Foram, a princípio, selecionadas as plantas: Cajueiro (Anacardium occidentale L); Girassol (Helianthus annuus L.); Gavadinha (Araceae sp); Mangueira (Mangifera indica L.); Hortelã (Plectranthus amboinicus (Lour.) Spreng.); Erva cidreira (melissa officinalis L.); Mandioca (Manihot esculenta Crantz); Cana-de-açúcar (Saccharum officinarum L.). Todas, espécies vegetais comuns e amplamente conhecidas no agreste alagoano. Fez-se cortes histológicos nos diversos órgãos vegetais das espécies e selecionou-se as plantas cujos cortes eram facilmente realizados, combinado com a obtenção de boas imagens.

Os órgãos vegetais foram utilizados ainda frescos no laboratório para realização dos cortes no laboratório multidisciplinar do campus I da UNEAL, utilizando lâminas cortantes e isopor para os cortes, resultando em secções finas dos tecidos para observações ao microscópio óptico. Em seguida os cortes foram colocados em placa de Petri contendo hipoclorito, após alguns segundos o hipoclorito foi removido das secções com água destilada em abundância e, por fim, foi feita a aplicação de um dos corantes. Posteriormente as secções foram colocadas em lâminas, com uma gota de água, onde a lamínula foi colocada por cima, nas lâminas selecionadas foram aplicados esmalte incolor, após retirada do excesso de umidade, pelo processo de lutagem. Em parte das amostras selecionadas foram colocados corantes para visualizar estruturas específicas. Utilizou-se celulares para fotografar o material ao microscópio.

Foram selecionados os métodos mais fáceis e possíveis de aplicação nas escolas de educação básica e as plantas selecionadas foram aquelas com estruturas mais visíveis e de fácil compreensão.

\section{Resultados e discussão}

Após avaliação dos resultados obtidos, selecionou-se as técnicas histológicas mais simples, facilmente possíveis de utilizar nas escolas de educação básica, e materiais botânicos e para preparação de atividades acessíveis e comumente encontrados na região agreste e semiárida do nordeste brasileiro, especialmente nas comunidades onde as escolas se encontram. Apesar de que diversos materiais relacionados ao trabalho desenvolvido são encontrados na 
literatura pertinente, destaque-se que a questão central do trabalho está no uso de plantas conhecidas na região, cujos materiais histológicos praticamente não são encontrados nos livros de educação básica.

Observou-se que com o uso dos materiais simples, propostos no planejamento da atividade, para realização de cortes histológicos manuais, pode-se visualizar estruturas internas de órgãos vegetais com qualidade suficiente para servir de estudos nos processos de ensino aprendizagem, o que pode ser observado nas imagens especificadas neste trabalho. Nos cortes histológicos obtidos, e sugeridos para a educação básica, observou-se facilmente estruturas como parede celular, epiderme, córtex, parênquima paliçádico, parênquima lacunoso, endoderme, vasos de xilema e floema, além de organelas como núcleo.

Assim, na Figura 3 observa-se a epiderme retirada da vargem da planta do feijão. O material em questão foi resultado do uso de uma técnica simples, que foi o uso de esmalte para unha, conhecido também como verniz para unha. O esmalte incolor foi aplicado sobre a superfície externa da vargem e após 30 minutos, quando o esmalte estava seco, o mesmo foi retirado com uma pinça pequena, colocado em uma lâmina contendo uma gota de água, posteriormente colocou-se uma lamínula sobre o material a ser observado. Ao microscópio óptico comum, observou-se a imagem constante na Figura 3.

Figura 3. Estômatos abertos observados ao microscópico da vargem do feijão.

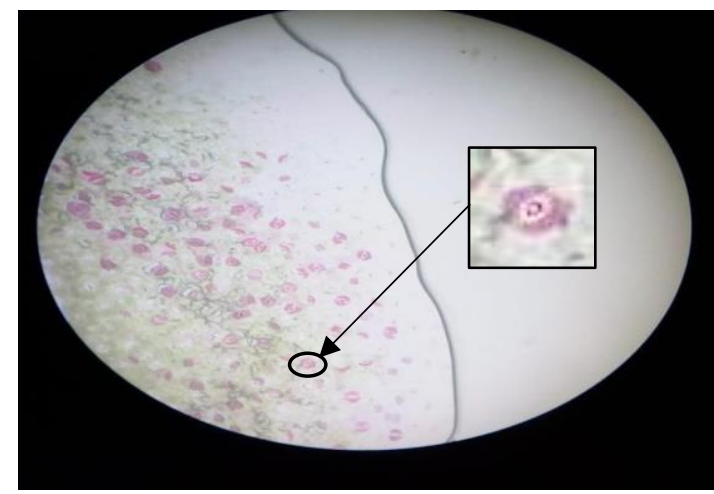

Fonte: arquivo da pesquisa. Autor: SILVA, L. E. B.

Verifica-se na Figura 3, em destaque, os estômatos, no caso com suas células guardas cheias o que permite a abertura dos ostíolos.

Na Figura 4 têm-se a imagem de estômatos fechados da vargem do feijão, cujo material foi obtido, também com uso de esmalte para unha, só que a aplicação do mesmo ocorreu durante o período noturno, nota-se que os estômatos estão fechados, ou seja, os ostíolos não estão abertos, e observa-se ainda, as células hexagonais típicas de parênquima.

Figura 4: Estômatos fechados observados ao microscópico da vargem do feijão.

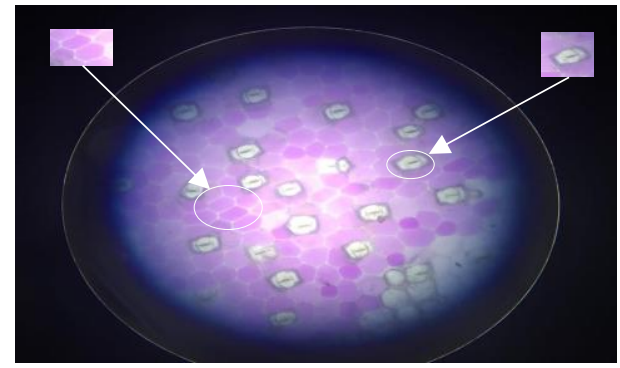


Fonte: arquivo da pesquisa. Autor: SILVA, L. E. B.

Os resultados descritos anteriormente estão condizentes com Taiz et al. (2017) que citam a abertura dos estômatos em diversas plantas durante o dia e fechamento dos mesmos à noite. Esse resultado é importante quando trata-se de despertar o interesse dos alunos da educação básica, visto que os mesmos poderão ter uma oportunidade de ver na prática o que é ministratado durante a aula teórica. Na Figura 5 têm-se a imagem de células da catáfilo da cebola destacando-se o núcelo.

Figura 5: Núcleo celular em células do catáfilo da cebola (Allium cepa L.).

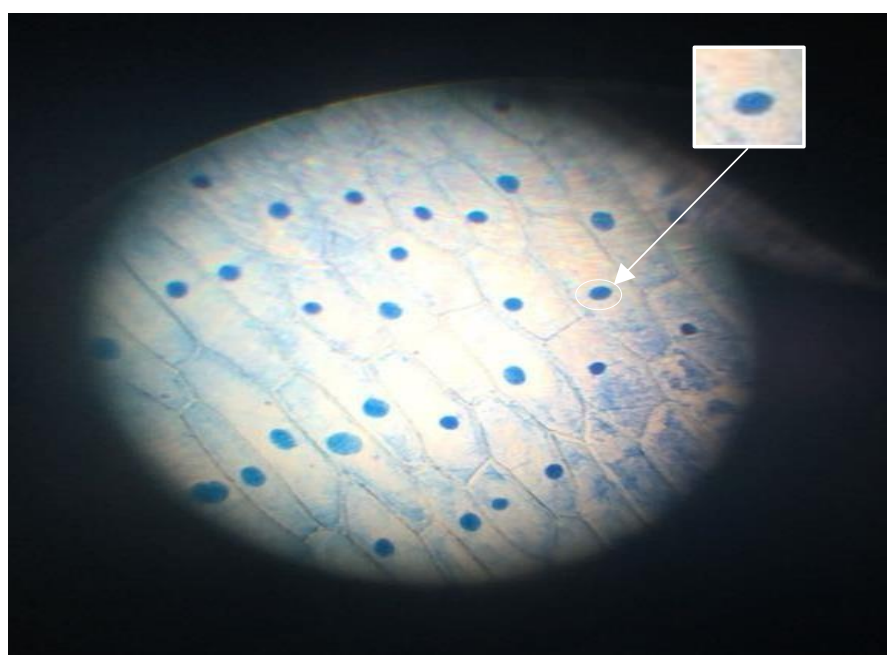

Fonte: arquivo da pesquisa. Autor: SILVA, L. E. B.

Outra imagem facilmente obtida, que apesar de comum em vários livros da educação básica, importa aqui é a forma de obtenção. Para obtenção da imagem da Figura 5 foi utilizado o bulbo da cebola, lâmina, lamínula e azul de metileno, cortou-se um pedaço recortado de um catáfilo de cebola, colocou em lâmina e posteriormente esperou-se 2 minutos para que pudesse, entao, cobrir com uma lamínula. Levou-se o material para observação ao microscópio, para observação. O referido corante reage com o núcleo que fica tingido na cor azul. Logo, tem-se mais uma forte relação entre teoria e prática, onde os alunos visualizaram com facilidade o núcleo de uma célula vegetal de uma planta encontrada na comunidade.

Na Figura 6, verifica-se um corte histológico do pecíolo da folha da planta Girassol (Helianthus annuus L.). O corte foi transversal, realizado com lâmina de barbear para navalhete, após retirar uma fina camada do pecíolo, o material foi colocado em uma lâmina de vidro com uma gota de água destilada, utilizou-se azul de metileno e então colocou-se lamínula e levouse para observação ao microscópio óptico, para análise. 
Figura 6. Visualização de corte histológico do pecíolo de Girassol (Helianthus annuus L.).

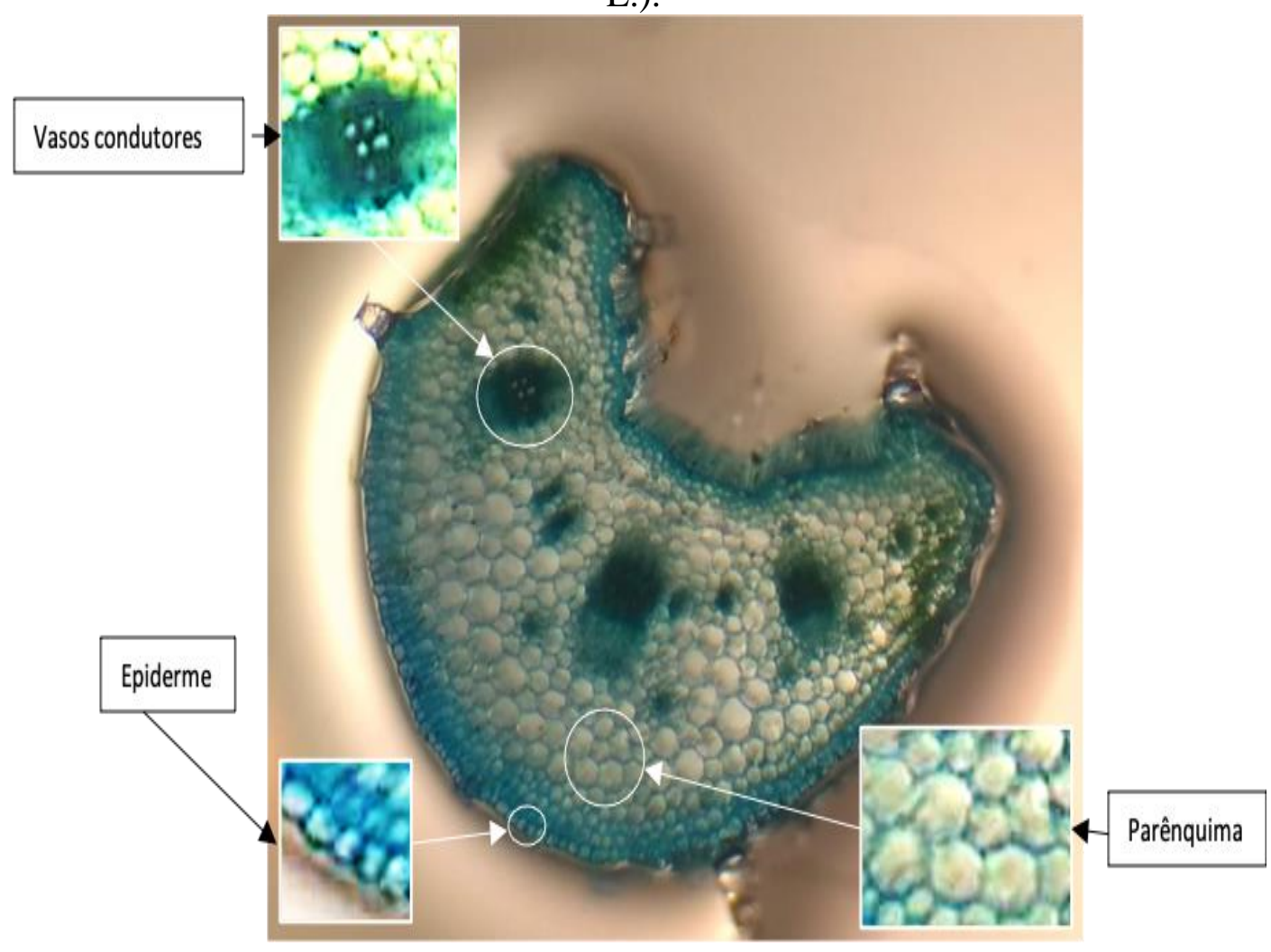

Fonte: arquivo da pesquisa. Autora: SANTOS, M. I. G.

No material analisado (Figura 6), observou-se claramente tecidos vegetais diferentes. Verificou-se a epiderme junto ao tecido parenquimatoso e imerso no tecido parenquimatoso detectou-se os feixes de vasos condutores.

O material visualizado facilidade a compreensão sobre tecido de revestimento e como o mesmo se dispõe no órgão vegetal, sobre os tecidos parenquimatosos e sobre os vasos condutores. Ao visualizar a o material durante as aulas teóricas o aluno pode despertar para os diversos tecidos e, assim, compreender melhor a importância dos mesmo para o vegetal. Fortalece o quão é importante desenvolver atividades nas escolas de educação básica buscando fazer uma relação entre teoria e prática no processo de ensino aprendizagem.

$\mathrm{Na}$ Figura 7, consta o corte histológico realizado no caule de um Girassol (Helianthus annuus L.). O corte foi feito com o auxílio de uma lâmina de barbear para navalhete. Após o corte, o material foi colocado em lâmina vidro contendo uma gota de água, utilizou-se como corante o azul de metileno e, posteriormente, colocou-se a lamínula sobre o material a observar, ficando o mesmo entre a lâmina e a lamínula. Nota-se claramente, apesar da simplicidade do corte transversal realizado e da possibilidade do mesmo ser feito até mesmo em uma sala de aula, a presença de tricomas (pêlos), da epiderme, dos feixes vasculares e da medula preenchida por parênquima. Mas uma vez fica evidente a hipótese do uso de aulas práticas nas escolas de 
Revista da Universidade Estadual de Alagoas/UNEAL

e-ISSN 2318-454X, Ano 13, Vol. 13 (2), 2021

educação básica sem exigir grandes esforços do docente e dos discentes para que a aula prática aconteça.

Figura 7: Amostra do corte histológico do caule, sendo possível a visualização da epiderme, parênquimas, tricomas e feixe vascular.

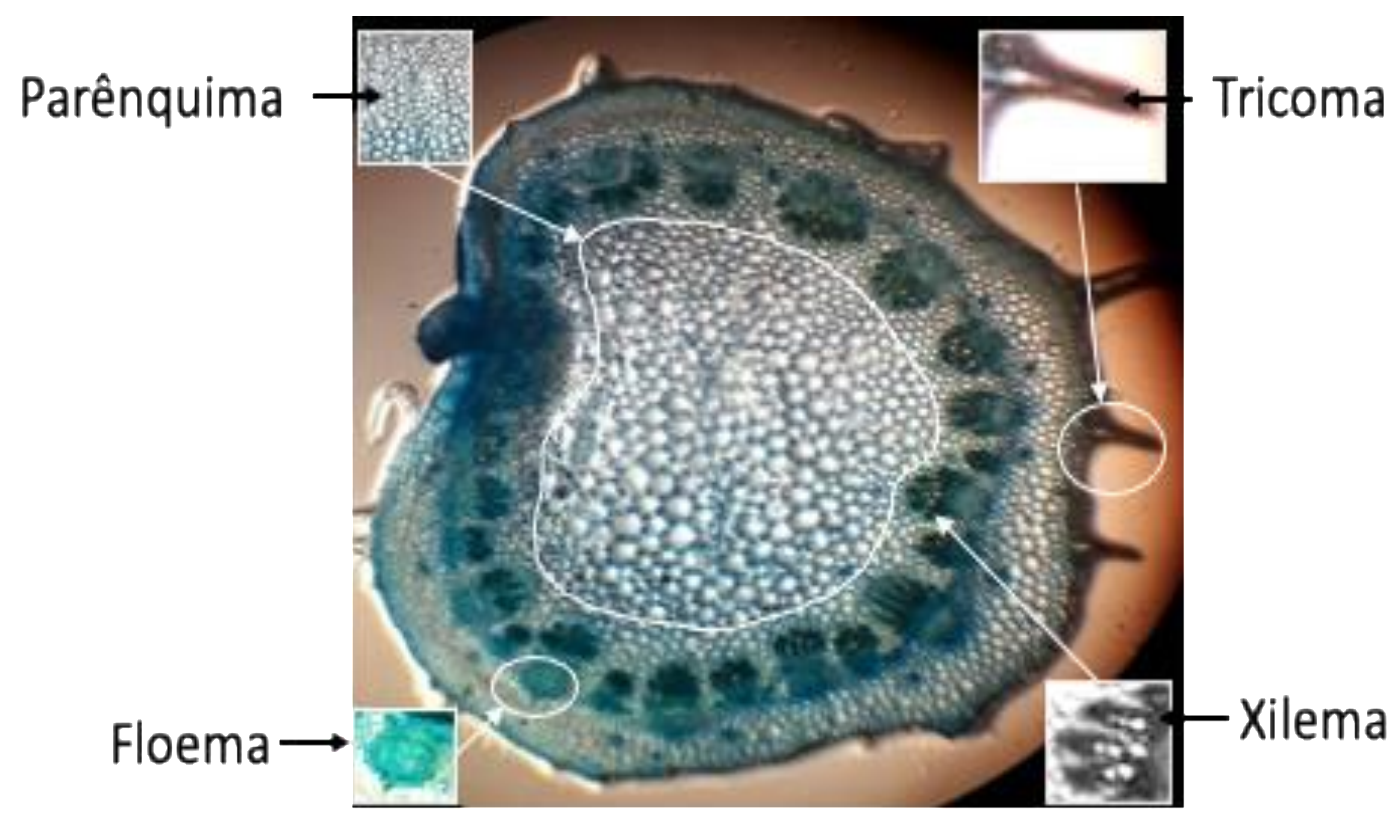

Fonte: arquivo da pesquisa. Autora: SANTOS, M. I. G.

Figura 8: Visualização da bainha da cana-de-açúcar (Saccharum officinarum L.).

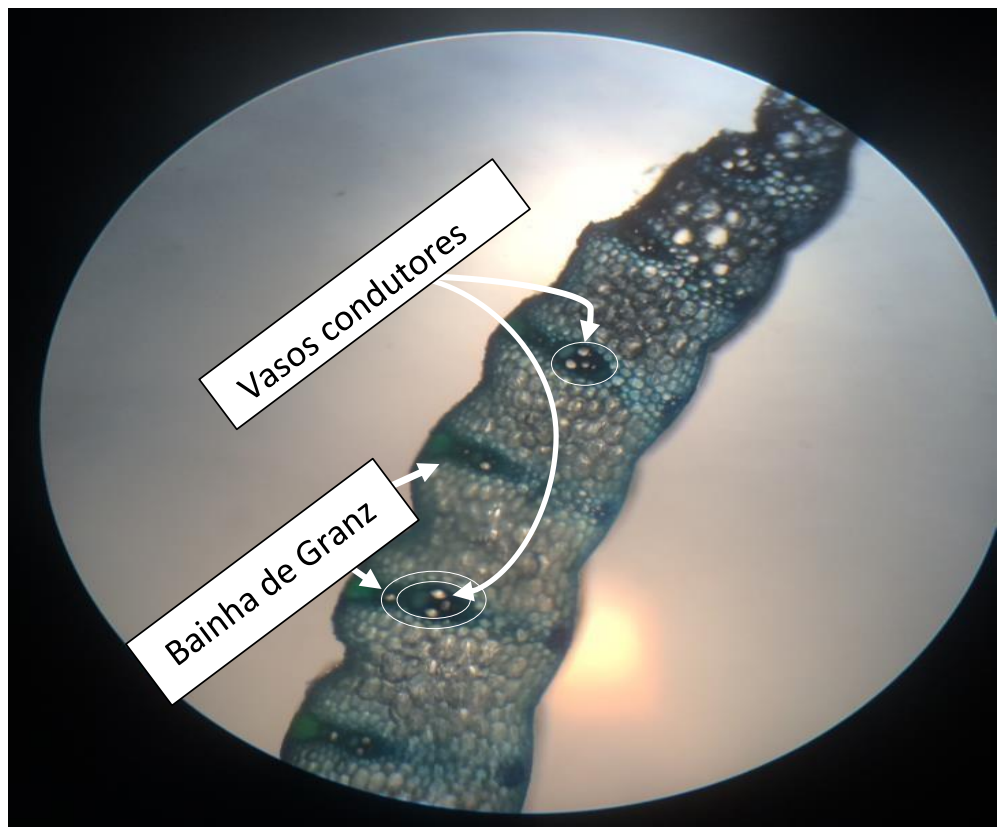

Fonte: Arquivo da pesquisa. SANTOS, R. L. V. 
Observar a bainha de Granz permite compreender melhor a diferença da disposição dos feixes de vasos condutores de grupos de diferentes plantas. Como por exemplo comparar a disposição dos feixes observados nas Figuras 6 e 7 com as imagens da figura 8. Nas Figuras 6 e 7 os feixes denunciam que os materiais observados são de plantas do grupo de dicotiledóneas (nomenclatura comumente encontrada nos livros didáticos), enquanto na Figura verifica-se os feixes típico de plantas do grupo da monocotiledôneas.

Notou-se portanto, que é possível visualizar as estruturas internas dos órgãos vegetais estudados quando se faz cortes histológicos dos órgãos da planta com técnicas simples. Ao microscópio foi possível observar diferentes tipos de estruturas encontradas principalmente em folhas e caule, a exemplo dos estômatos, núcleos celulares, epidermes, parênquima, colênquima e feixes vasculares, além de uma visão geral das células vegetais, trazendo assim, a possibilidade de uso dessas plantas nas escolas de educação básica sob o ponto de vista da morfologia vegetal.

\section{Conclusão}

O professor como facilitador e mediador da construção de um conhecimento motivador para a compreensão das ciências, no caso da biologia, pode e deve utilizar aulas práticas facilitando o processo de ensino aprendizagem. Os resultados obtidos certificam que o experimento é fácil, possível e proporciona experiências que devem ser vividas em sala de aula, levando os alunos e futuros professores a entender que pode ser feito, que melhora a forma ministrar aula e aprender, sobretudo nas escolas da rede publica de ensino, onde pode-se encontrar uma grande deficiência no quesito aprendizagem, que possui muita relação com a falta de materiais para aulas práticas e também a falta de conhecimento de diversos professores acerca de novas práticas no ensino da biologia vegetal. O trabalho ratificou uma experiência acerca da utilização das práticas pedagógicas no ensino da biologia vegetal, podendo contribuir para melhoria do ensino.

\section{Conflitos de interesse}

Os autores deste manuscrito não declararam conflitos de interesse.

\section{Referências}


CALLEGARIO, L.J. e BORGES, M.N. Aplicação do vídeo "Química na Cozinha" na sala de aula. In: Encontro Nacional de Ensino de Química, 15, 21 a 24 de julho de 2010. Caderno de resumos. Brasília: 2010.

DILLENBOURG, Pierre. Virtual Learning Environments. 2000.

LEITE, A. C. S.; SILVA, P. A. B.; VAZ, A. C. R. A importância das aulas práticas para alunos jovens e adultos: uma abordagem investigativa sobre a percepção dos alunos do PROEF II. Revista Ensaio, v. 7, n.3, 2005.

LOPES, S. Bio. Editora Saraiva, 2002.

MARANDINO, M. A Biologia nos Museus de Ciências: a questão dos textos em bioexposições. Ciência \& Educação, Bauru, v. 8, n. 2, 2002.

MENDES, R.; MUNFORD, D. Dialogando saberes: pesquisa e prática de ensino na formação de professores de ciências e biologia. Ensaio, Belo Horizonte, v. 7, n. 3, p. 4 -12 2005.

PAULINO, W. R. Biologia. São Paulo: Ática, 2005. ISNN ou ISBN.

PARÂMETROS CURRICULARES NACIONAIS (PCNs). Disponível em:<http:// www.portal.mec.gov.br>. Acesso em: Março de 2021.

QUEIROZ, K. de M. Produção de multimídia sobre técnicas de Anatomia e Morfologia Vegetal com plantas encontradas na região de Arapiraca-AL, para aulas práticas na educação básica. 2016. 55 f. Trabalho de Conclusão de Curso-Universidade Estadual de Alagoas, Arapiraca, 2016.

TAIZ, L.; ZEIGER, E.; MOLLER, I.; MURPHY, A. Fisiologia e desenvolvimento vegetal. 6.ed. Porto Alegre: Artmed, 2017. 888 p. 